\title{
An Analysis of Surface Ocean Currents from HF Radar Measurements in the Bali Strait and the Flores Sea, Indonesia
}

\author{
Eko Supriyadi $^{\mathrm{a}, \mathrm{b}, *}$, Rahmat Hidayat ${ }^{\mathrm{a}}$, I Putu Santikayasa ${ }^{\mathrm{a}}$, Andri Ramdhani ${ }^{\mathrm{b}}$ \\ ${ }^{a}$ Department of Geophysics and Meteorology, IPB University, Darmaga, Bogor, 16680, Indonesia \\ ${ }^{b}$ Center for Marine Meteorology, Meteorology Climatology and Geophysics Agency (BMKG), Jakarta, 10720, Indonesia \\ Corresponding author: *eko.supriyadi@bmkg.go.id
}

\begin{abstract}
Analyze Surface Ocean Currents (SOCs) with one year of HF Radar data (2018-2019) for each season to determine the characteristics of the SOC direction and speed of the crossing route and its control factors carried out in the Bali Strait and the Flores Sea. Method of data analysis by computing the SOC speed and direction of the zonal and meridional components. The results showed that the SOC pattern in the Bali Strait affects the season where its speed in the DJF season is lower than the JJA season. Moreover, the SOC direction in the Bali Strait is dominant towards the south due to the influence of bathymetry. Meanwhile, the SOC pattern in the Flores Sea has a random pattern every season for the influence of topography in the form of small islands that influence the SOC dominant pattern. Furthermore, the SOC characteristics on the Bali Strait crossing route throughout the month are divided into two patterns: random on the eastern side of East Java Island and dominant towards the south on the west side of Bali Island with a maximum speed of $83 \mathrm{~cm} / \mathrm{s}$. Meanwhile, the crossing route in the Flores Sea is random, with a maximum speed of $32 \mathrm{~cm} / \mathrm{s}$. Whereas, based on the normal cross-correlation method, the SOC control factors in the Bali Strait tend to be influenced by tides, while the factors in the Flores Sea are less influential based on the distribution of zonal and meridional currents of HF Radar.
\end{abstract}

Keywords - Surface ocean currents; HF radar; Bali strait; Flores sea; tides-wind.

\section{INTRODUCTION}

Apart from being included in an in-situ maritime observation, HF Radar is also classified as a remote sensing device [1]. According to the International Telecommunications Union, the HF Radar device works at a frequency of 3-30 MHz of radio waves [2]. At high frequencies, it will produce a small observation area that has a high resolution. Conversely, at low frequencies, it will produce a wider observation area with low-resolution results. Therefore, the installation of HF Radar in a site depends on the conditions of the area and similar frequency interference. The working principle follows the Bragg and Doppler formula [3], [4]. When radio waves from HF Radar hit the ocean's surface, it might produce a backscattering of moving ocean waves. This backscattering is known as Bragg scattering, which will be observed as a peak in the energy spectrum. The object approaches the radar if the largest spectrum energy peak falls on a positive Doppler frequency. In contrast, the object moves away from the radar if it falls on a negative Doppler frequency. This Doppler frequency value has then calculated the difference with the HF Radar frequency to produce the shift frequency [5], [6]. This shift frequency is calculated as the current radio velocity, enabling the SOC vector to be calculated. In the formula, the relation between Bragg scatter, Doppler, and shift frequency is formulated as $\mathrm{v}_{\mathrm{r}}=\Delta \mathrm{f} / 2 \lambda$.

The HF Radar development history as a SOC measuring device was started back in the 1950s. Crombie [7] studied the reflection of sea surface radar waves based on the Doppler principle at $13.56 \mathrm{MHz}$. It was discovered for the first time that the ocean's wavelength was half the length of radio waves, and the change in the Doppler frequency was constant regardless of the surrounding wind and sea conditions. This opens further studies on the use of HF Radar at sea level. From 1970 until now, HF Radar was rapidly developed and commercially available in the world [8]-[10]. Currently, two main producers produce HF Radar products, CODAR and WERA [11], [12]. In total, there have been 400 HF Radar devices installed since March 2019. The device is spread across 42 countries, with ten countries participating in disseminating SOC data that can be accessed at http://global- 
hfradar.org/. From the JCOMM [13] data, the United States is the largest HF Radar user country with 144 units, followed by Korea and Japan with 26 and 22 units, respectively.

Several studies related to the use of HF Radar to measure SOC have been carried out. For example, the use of HF Radar to study the SOC characteristics in the Ariake Sea, Japan by Aoki and Kataoka [14], the development of a short-term prediction system to map SOC from HF Radar measurements by Ren et al. [15], the use of instruments to find the correlation between SOC and model by Orasi et al. [16], and assimilation of HF Radar with models to improve forecast capability during tropical cyclone by $\mathrm{Li}$ and Toumi [17]. However, a study on the utilization of HF Radar and its application in Indonesia to measure SOC has never been carried out up to now. From the literature review, a study on the comparative analysis method wave spectrum of HF Radar has been conducted by Lukijanto et al. [18]. However, it was done in the South of England waters, not in Indonesian waters. Furthermore, Iswandi [19] only explained the HF Radar mechanism and compared it with other tsunami sensors, not in the application and data processing.

However, several references state that SOC can be influenced by generating factors originating from the atmosphere and oceans, such as wind and tides [20]-[22]. Previously, Wyrtki [23] had explained that the wind had an influence in the movement of SOC along the equator, especially $60^{\circ}-90^{\circ}$ east longitude. Meanwhile, Pond and Pickard [24] provide another explanation in which they decide SOC movements based on the influence of differences in density, wind, tides, seismic ocean waves, turbulence, and other motion variations such as internal forces Rossby waves, and gravitational waves. Stewart [25] and Ogata et al. [26] also includes that SOC could be affected by tsunamis and tides. Thus, it is known that the SOC generating factor can be generated either from the influence of the atmosphere, oceans, or the interaction of the two.

On the other hand, marine SOC information is needed by maritime service users, such as fishermen, skippers, marine tourism activists, and coastal communities themselves. In fact, in some cases, knowing the SOC pattern can help the search and rescue team in a sea accident. Many examples show that SOC is still a significant obstacle during an accident in Indonesian waters. For example, in the case of the oil spill in Balikpapan Bay on 31 Mar. 2018, the crash of the Lion Air plane in Karawang waters on 28 Oct. 2018, the crash of Sriwijaya Air at Jakarta Bay on 9 Jan. 2021, and the most frequent occurrence was the decrease in the catch of fishers. Unfortunately, currently, there is no real-time and highresolution SOC information in Indonesia. Learning this condition, the Marine Meteorology Center of the Meteorology, Climatology, and Geophysics Agency (BMKG) since October 2018 has operated HF Radar in two locations, Bali Strait and the Flores Sea. The two locations were chosen since they have relatively high shipping frequency and favorite domestic and foreign tourist routes that require ferry safety. Based on the explanation above, this study examines: (1) validate HF Radar output, (2) analyze the SOC produced by HF Radar in the Bali Strait and the Flores Sea as well as its crossing routes, and (3) lastly, the study on the effect of atmosphere-ocean on SOC in these two locations has never been carried out.

\section{MATERIALS AND METHOD}

Following the purpose of this paper, the method section will be started by performing HF Radar validation against ADCP in section II.A. The SOC characteristics are diurnal, seasonal, and the crossings that are the main objectives of this research are described in section II.B. The last explanation of the factors affecting the SOC is in the II.C section. In order, the results of the method are described in section III.

The primary data used in this study comes from HF Radar located in the Bali Strait and the Flores Sea from 1 Oct. 2018 to 30 Sept. 2019. The Bali Strait is a strait that separates Java and Bali Islands. The Bali Sea borders the North of the Bali Strait, while the Indian Ocean borders the South. As seen from the map, the shape of Bali Strait is cone-shaped with a narrow part on the north side and a wide part on the south side. Meanwhile, the Flores Sea is located in the northern part of the Nusa Tenggara Islands. This sea stretches from West Nusa Tenggara Island in the west to Alor Island in the east. The north side is directly adjacent to the Java and Makassar Seas. The bathymetry value of the Flores Sea has a large change in depth and can reach more than $5000 \mathrm{~m}$ [27]. Both the Bali Strait as well as the Flores Sea are in the Java-Nusa Tenggara Island cluster (Figure 1a-c).

The data recorded in this device are ocean currents with a data recording duration of every 20 minutes for Bali Strait and 30 minutes for the Flores Sea. For validation purposes, the Acoustic Doppler Current Profiler (ADCP) device was also used in this study with an observation interval on 24 Apr. 201909.00 to3 May 201909.50 (local time). In Automatic Weather Station (AWS) maritime, the data employed includes the water level as well as wind direction and speed at the scene. These devices in the Bali Strait was also utilized for further analysis.

\section{A. HF Radar data validation technique}

Before further processing, the instrument HF Radar data was validated using ADCP, considering that the current HF Radar is a remote sensing device that still requires validation from an onsite device. The current data generated by the ADCP comes from a depth of $2.5 \mathrm{~m}$ above sea level. Thus, compared to the HF Radar, which records surface currents, it might not be balanced. As a result, a filtering process was required in processing the data [28]. The filtering technique employed was the 36-hour Finite Impulse Response (FIR) low-pass filter. The value of 36 appeared as the spectral period of HF Radar and ADCP energy starting to decrease through the Fast Fourier Transform (FFT) technique. This value was also used as the cut-off (limit) of the low-pass filter. Furthermore, the filter process was carried out using the Hamming function [29] (p. 473):

$$
\begin{gathered}
\mathrm{H}(\mathrm{n})=0.54+0.46 \cos \left(\frac{2 \pi \mathrm{d}}{\mathrm{D}}\right) \\
\mathrm{d}=-D / 2, \ldots, \mathrm{D} / 2
\end{gathered}
$$

where $\mathrm{D}$ is the length of the data used. This Hamming function was then used as a rational transfer function [30]:

$$
\mathrm{F}(\mathrm{z})=\mathrm{f}_{\mathrm{c}}(1)+\mathrm{f}_{\mathrm{c}}(2) \mathrm{z}+\ldots+\mathrm{f}_{\mathrm{c}}(\mathrm{n}+1) \mathrm{z}^{-\mathrm{n}}
$$

where $f_{c}$ is the filter coefficient and $z$ is the z-transform variable of the $F(z)$. 


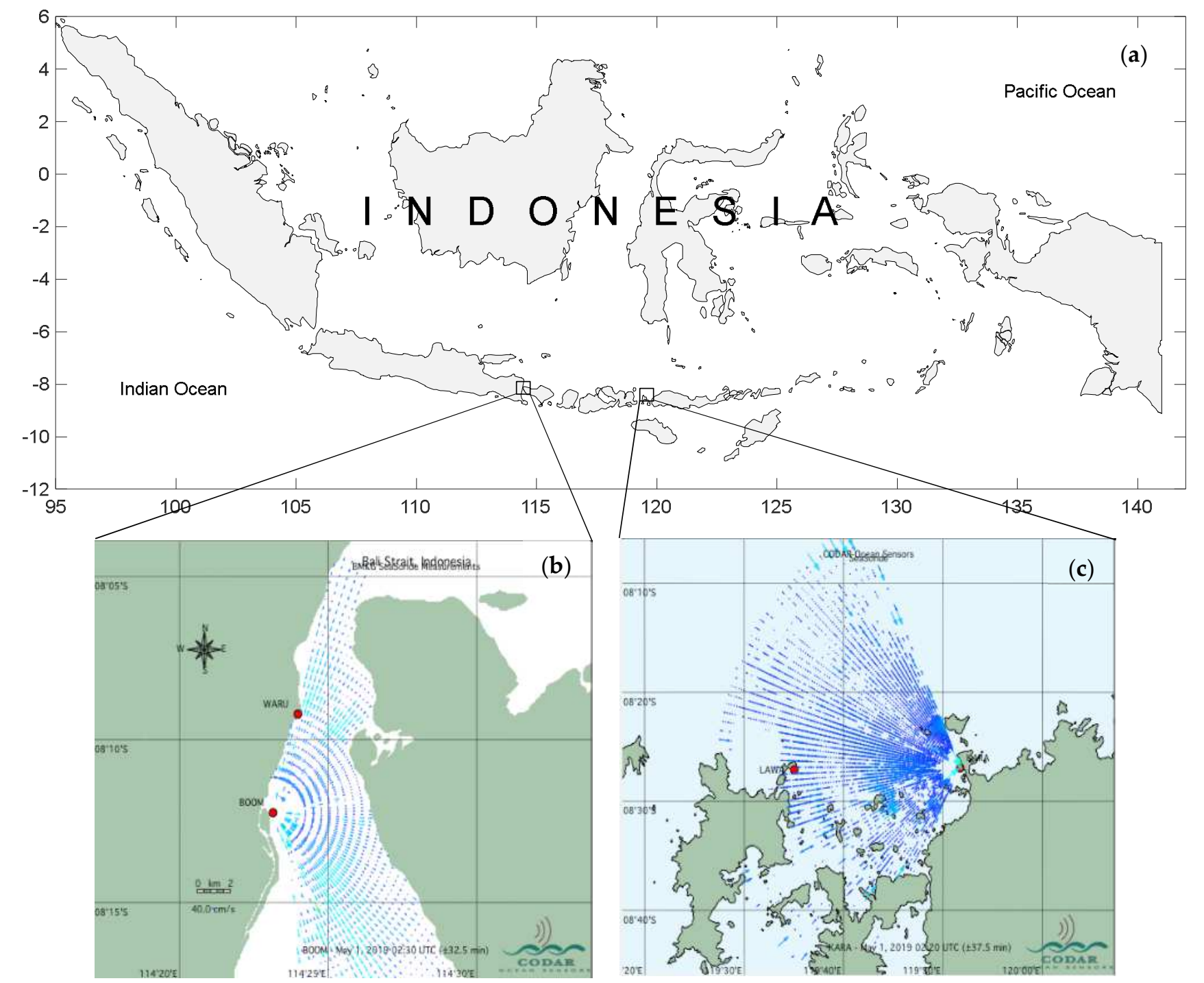

Fig. 1 (a) The Indonesian maritime continent. The location of the HF Radar instrument is marked four a red dot. Two HFRs are located at BOOM and WARU in the Bali Strait (b) and in the LAWA and KARA in the Flores Sea (c). The blue radial represents the HF Radar measurement range, and the black asterisk is the location the ADCP is installed.

Equation 1-2 was employed to the ADCP and HF Radar data. Then, further statistical analysis was carried out using the Root Mean Square Error (RMSE), the coefficient of determination $\left(\mathrm{r}^{2}\right)$, and the Index of Agreement (IA) [31]:

$$
\begin{aligned}
& \mathrm{RMSE}=\sqrt{\frac{\sum_{\mathrm{i}=1}^{\mathrm{n}} \mathrm{v}_{\mathrm{HFR}(\mathrm{i})}-\mathrm{v}_{\mathrm{ADCP}(\mathrm{i})}}{\mathrm{n}}}
\end{aligned}
$$

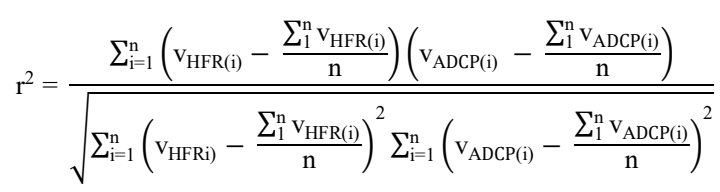

$$
\begin{aligned}
& \mathrm{IA}=1-\frac{\mathrm{MSE}}{\sum_{1}^{\mathrm{n}}\left(\left|\mathrm{v}_{\mathrm{HFR}(\mathrm{i})}-\frac{\sum_{1}^{\mathrm{n}} \mathrm{v}_{\mathrm{ADCP}(\mathrm{i})}}{\mathrm{n}}\right|+\left|\mathrm{v}_{\mathrm{ADCP}(\mathrm{i})}-\frac{\sum_{1}^{\mathrm{n}} \mathrm{v}_{\mathrm{ADCP}(\mathrm{i})}}{\mathrm{n}}\right|\right)^{2}}
\end{aligned}
$$

where $\mathrm{n}, \mathrm{v}_{\mathrm{HFR}}$, and $\mathrm{v}_{\mathrm{ADCP}}$ are the total data, HF Radar and ADCP are speed currents, respectively. IA $=1$ describes perfect agreement, whereas IA $=0$ describes no agreement. While the coefficient of determination describes the closeness of the two results: the greater the value, the closer the relationship. Finally, The RMSE values indicate the distance or proximity of the distribution of the HF Radar results to ADCP observations. The lower of RMSE value, the better the results of the HF Radar measurement.

\section{B. Characteristics of SOC in Bali Strait and the Flores Sea}

HF Radar data contains coordinate variables, time, and current components. The SOC speed calculation was done using the following equation:

$$
\text { curr }=\sqrt{\mathrm{u}^{2}+\mathrm{v}^{2}}
$$

where $\mathrm{v}$ and $\mathrm{u}$ are the component of meridional and zonal current, respectively. Additionally, the SOC $(\theta)$ direction was also calculated using the following equation:

$$
\theta=\arctan \frac{\mathrm{v}}{\mathrm{u}}
$$

Pay attention to equation (7); the reference angle formed is the east direction. However, in navigation, the reference for measuring an angle is the north direction. Thus, equation (7) was modified to:

$$
\varnothing=90-\theta
$$


The calculation started from October 2018 to September 2019. It was divided every three months according to the monsoonal effects that commonly occur in the ocean, the DJF season (December, January, February), MAM season (March, April, May), JJA season (June, July, August), and the SON season (September, October, November) [32]. HF Radar conducted SOC observations every 20 and 30 minutes in the Bali Strait and the Flores Sea during the measurement, respectively. To analyze the SOC for each season, the above three-month average calculations are made:

$$
\overline{\operatorname{curr}}=\frac{\sum_{\mathrm{i}=1}^{\mathrm{n}} \operatorname{curr}_{\mathrm{i}}}{\mathrm{n}}
$$

the results of the monthly validation and processing of SOC data in the Bali and Lombok Strait are presented in the results and discussion section.

Moreover, the direction and speed of SOC were determined on shipping lanes in the Bali Strait and Flores Sea (Figure 2). There are two main ports in Bali Strait, Gilimanuk and Ketapang. Gilimanuk Port is at coordinates of $114.39750^{\circ}$ west latitude and $-8.1591^{\circ}$ south longitude. Meanwhile, Ketapang Port is at coordinates of $114.4293^{\circ}$ west latitude and $-8.1681^{\circ}$ south longitude. From the coordinates of Gilimanuk Port to Ketapang Port, 8-line segments were set with intervals of $0.0045^{\circ}$. This number has been adjusted to the HF Radar resolution to simplify calculations (Figure 2a). Furthermore, from the 8-line segments, the direction and speed of SOC were seen each season. It might then be seen in what position and month the optimal current to support the navigation.

In the Flores Sea, on the east side of the map, the port included in the HF Radar observation scope is Labuhan Bajo, while there is no port on the west side (Figure 2b). This is due to the limited range of HF Radar observations. However, the line segments were still drawn representing the crossing route from Labuhan Bajo to Bali, for this route is the largest crossing route on the East Nusa Tenggara Island. Labuhan
Bajo Port is at the coordinates $119.8212^{0}$ west latitude and $8.4778^{0}$ south longitude, while the west side of the map is then named point $X$ at the coordinates 119.61220 west lat and $8.3783^{\circ}$ south longitude. With an interval of $0.0045^{\circ}, 24$ segments were formed, henceforth, to see the direction and speed of SOC each month.

\section{SOC control factors in the Bali Strait and Flores Sea}

Then, to determine the generating factors that affect SOC in the Bali Strait and Flores Sea, wind speed and water level data were utilized from the AWS of each location. Since there was no AWS equipment in the Flores Sea, the analysis was conducted using a comparison of $u$ and $v$ velocity components [33]. If the distribution of data $u$ and $v$ forms an ellipse, the dominant SOC is effect by tides.

Variations in the water level value of a location are influenced by the moon's movement [25]. For this reason, the available water level, wind speed, and SOC data were separated based on the Hijri month. Further exploration was carried out to see the patterns of the three parameters. Furthermore, since the wind speed and water level data were time-series data, there is likely blank data that enable the running average to be carried out through the equation [34]:

$$
\begin{aligned}
\mathrm{ws}_{\mathrm{i}} & =\frac{1}{\mathrm{M}_{\mathrm{o}}} \sum_{\mathrm{j}=0}^{M_{o^{-}}-1} \mathrm{ws}(\mathrm{i}-\mathrm{j}) \\
\mathrm{wl}_{\mathrm{i}} & =\frac{1}{\mathrm{M}_{\mathrm{o}}} \sum_{\mathrm{j}=0}^{M_{O^{-1}}} \mathrm{wl}(\mathrm{i}-\mathrm{j})
\end{aligned}
$$

Whereas for SOC from HF Radar using the following equation:

$$
\operatorname{curr}_{i}=\frac{1}{M_{o}} \sum_{j=0}^{M_{o^{-1}}} \operatorname{curr}(i-j)
$$
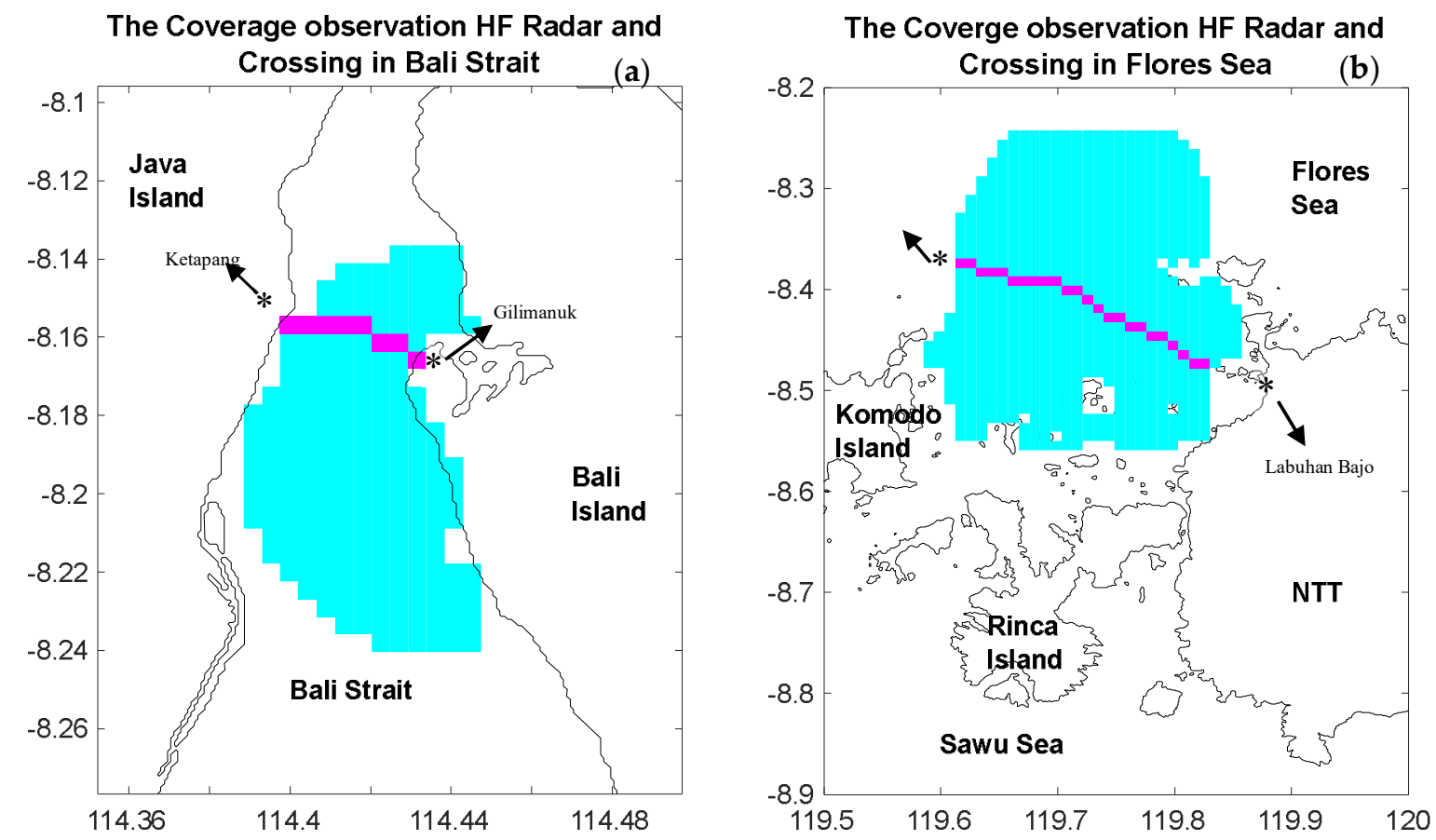

Fig. 2 The coverage of the SOC from HFR in the Bali Strait (a) and Flores Sea (b) is marked with cyan color, while the crossing route is marked with magenta. 
Where:

$M_{o}$ : the range of moving mean values, in this case, the value is 5

$\mathrm{wS}_{\mathrm{i}}$ : moving average value of wind speed

ws : initial wind speed data

$\mathrm{wl}_{\mathrm{i}}$ : moving average value of water level

wl : initial water level data

curr $_{i}$ : moving average value of current

curr : initial current data

Wind speed data $\left(\mathrm{ws}_{\mathrm{i}}\right)$, water level $\left(\mathrm{wl}_{\mathrm{i}}\right)$, and HF Radar currents that had been obtained were separated every hour. Thus, later it might produce an average hourly data for a year. This means that there were 24 data for each of the parameters above. The three-parameter values obtained were then plotted in a graph to see their similarities.

Furthermore, the main problem dealing with two or more time-series data is determining the pairwise similarity between them [35]. To overcome this problem, in the second methodology, the Normal Cross-Correlation (NCC) equation was applied to see to what extent the value of wind speed and the water level correlates with the SOC value of the HF Radar. The NCC equation is defined below [36]:

where:

$$
\mathrm{NCC}=\frac{\mathrm{C}_{12}(\tau)}{\sqrt{\mathrm{C}_{11}(0) \mathrm{C}_{22}(0)}}
$$

$$
\mathrm{C}_{12}(\tau)=\int_{-\infty}^{+\infty} \mathrm{z}_{1}(\mathrm{~s}) \mathrm{z}_{2}(\mathrm{~s}+\tau) \mathrm{dt}
$$

with $\mathrm{z}_{1}(\mathrm{~s})$ and $\mathrm{z}_{2}(\mathrm{~s})$ are the two-time series data being compared. The higher the NCC generated from the time series data pair shows a strong correlation between the two. On the other hand, if it is zero, it means that it does not correlate. In short, the three methodologies can be summarized in the above flowchart (Figure 3).

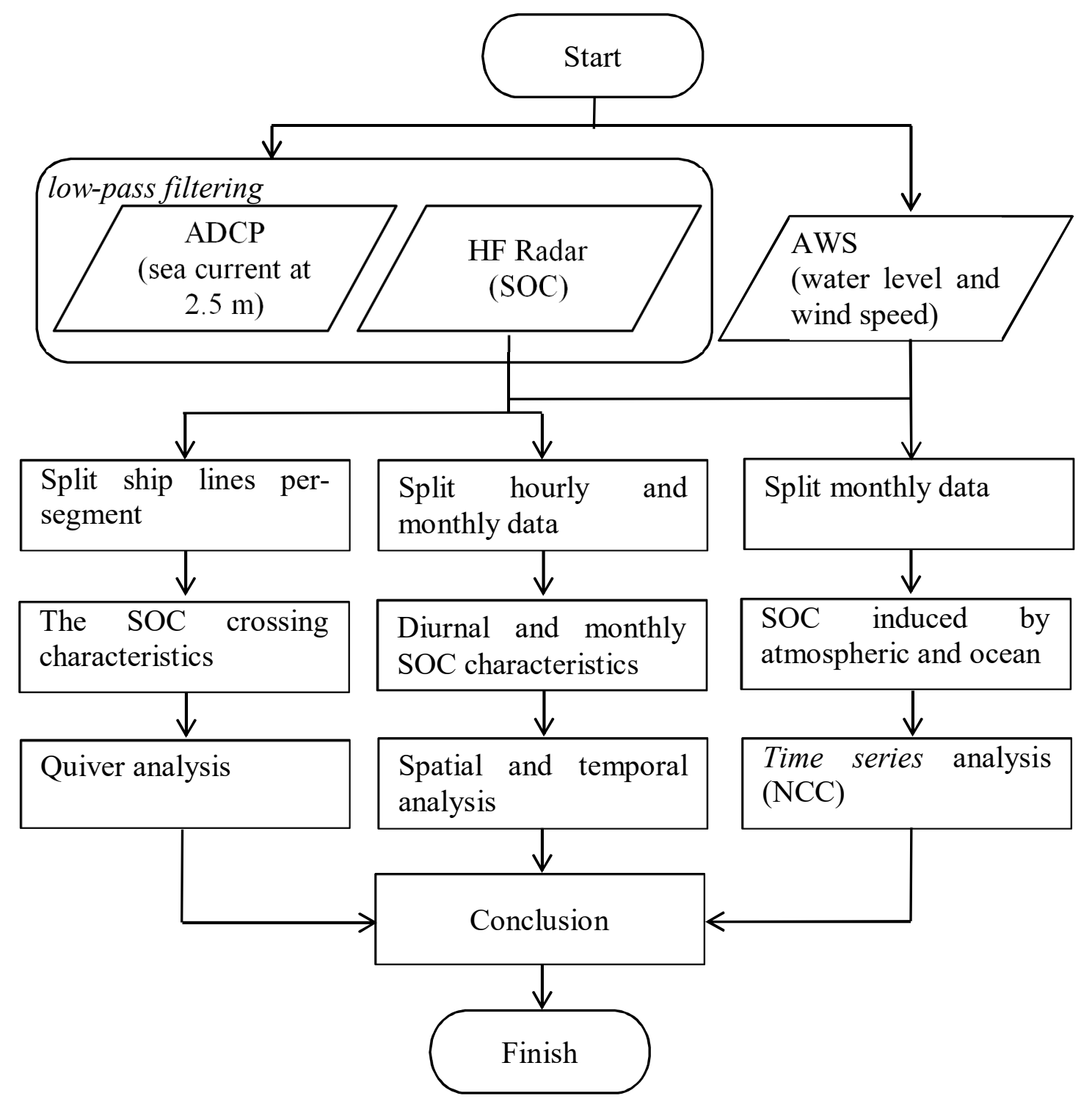

Fig. 3 Flowchart this study 


\section{RESULTS AND DISCUSSION}

\section{A. HF Radar Data Validation on ADCP}

Figure 4 presents a statistical analysis comparison between the SOC speed on HF Radar and ADCP with a 36-hour lowpass filtering technique. The HF Radar data period used follows ADCP installation time from 24 Apr. 2019, 09:00 to 4 May 2019, 09:40 (local time) to guarantee validation quality. It can be shown that during the observation period, the HF Radar measurement is higher than ADCP for the ADCP device measured at a depth of $2.5 \mathrm{~m}$. As a result, a regression formula in the form of $\mathrm{V}_{\mathrm{hfradar}}=\mathrm{a}+\mathrm{b} \cdot \mathrm{V}_{\text {adcp }}$ can be formed with the intercept value (a) at $[5.46 ; 11.93]$ and slope (b) $[1.87 ; 2.19]$. Additionally, the obtained RMSE and IA were $6.4 \mathrm{~cm} / \mathrm{s}$ and 0.99 , respectively. From these observations, it can be inferred that the output of HF Radar measurement can be used to study the SOC characteristics in the Bali Strait and the Flores Sea.

The result of the HF Radar validation with the ADCP in this study showed relevant results, for example, RMSE 6.4 $\mathrm{cm} / \mathrm{s}$ and correlation 86.4. This result is not much different from the study of Wei et al. [37], which obtained the RMSE range of $[7 ; 13] \mathrm{cm} / \mathrm{s}$ and correlation of $0.89-0.98$ with the same device. Several references have compared the HF Radar data output with other observation devices, such as the buoy device by Tian et al. [38], which obtained the RMSE range of $[11 ; 13] \mathrm{cm} / \mathrm{s}$. The use of a drifter set by Corgnati et al. [39] obtained the RMSE range of $[10 ; 22] \mathrm{cm} / \mathrm{s}$, and the current meter commonly installed in the hull by Cosoli and de Vos [12] obtained a range of $[17.4 ; 33.6] \mathrm{cm} / \mathrm{s}$. From the comparison, it can be seen that the use of various observation devices tends to produce different measurements, such as the difference in the time interval for data collection [40]. In this paper, ADCP and HF Radar took measurements every 10 and 20 minutes, respectively. However, according to Liu et al. [41], these two intervals are considered very well in sampling. Moreover, environmental influences such as interference with radiofrequency and metal (i.e., ships) can reduce the quality of HF Radar data.
Furthermore, the low-pass filtering technique used comes from the spectral period of HF Radar and ADCP energy starting to decline through the FFT technique. Other studies with similar devices tend to compare validation directly [42][44]. In contrast, many ocean phenomena produce highfrequency signals that must eliminate [29]. This study offers novelty in validation using low-pass filtering technique.

\section{B. Characteristics of SOC in the Bali Strait}

During the DJF season, the SOC pattern is relatively calm throughout the waters of the Bali Strait. According to the season, the current direction is divided into two major groups, namely heading north on the east coastal of Java Island and South on the west coastal of Bali Island. Specifically, in the southern part of the west side of Bali Island, the direction of the current was grouped into two, forming an eddy on the west side and another towards Bali Island (Figure 5a). During the DJF season, SOC speed is the lowest compared to other seasons. Meanwhile, SOC velocity at two ports, Gilimanuk and Ketapang, was recorded as $29 \mathrm{~cm} / \mathrm{s}$ and $41 \mathrm{~cm} / \mathrm{s}$, respectively. During the MAM season, there has been an increase in SOC speed on the western side of the Bali Island, ranging from $40-80 \mathrm{~cm} / \mathrm{s}$ with the new direction dominant to the South.

Additionally, lower SOC speed $(0-20 \mathrm{~cm} / \mathrm{s})$ was detected on the eastern side of Java Island with the direction of the current to the east to then join the current in the middle of the water to the South (Figure 5b). During this season, the SOC speed at Gilimanuk and Ketapang Ports was 73 and $6 \mathrm{~cm} / \mathrm{s}$. The JJA season is the season with the maximum SOC speed in the Bali Strait (Figure 5c). It can be seen that the west side of the island of Bali SOC speed can reach $140 \mathrm{~cm} / \mathrm{s}$ with the dominant current heading south. A different thing occurs on the eastern side of Java Island, where it is measured that the SOC speed is lower with a range of $0-40 \mathrm{~cm} / \mathrm{s}$. The SOC direction at this location was to the east and joined the current in the middle of the waters to the south where an eddy was detected at this location. During this season, the SOC speed at Gilimanuk and Ketapang Ports was 114 and $14 \mathrm{~cm} / \mathrm{s}$. Note that in this paper, all speed of SOC is expressed in $\mathrm{cm} / \mathrm{s}$.

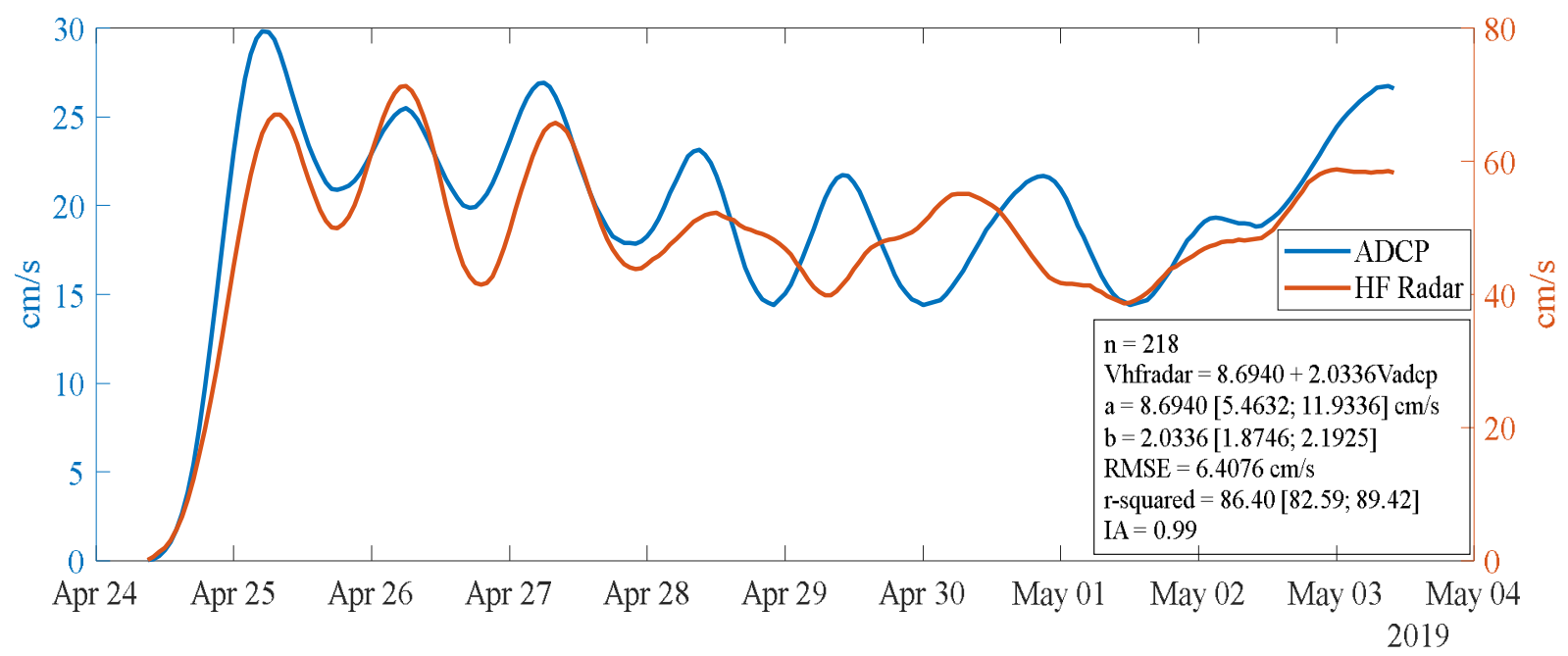

Fig. 4 Comparison instrument ADCP (blue) and HF Radar (brown) data in the Bali Strait using a 36-hour low-pass filter. The statistics are shown in the lower right box with the description: the number of data pairs ( $\mathrm{n}$ ); regression equation; regression intercept (a); regression slope (b); RMSE; coefficient of determination (r-squared) and IA. The values on [bracket] parameters a, b, and r-squared show a $95 \%$ confidence level. 
In the SON season, the resulting SOC pattern was not much different from the JJA season, but the speed had decreased considerably. The maximum SOC speed still occurred on the west side of Bali Island, $100 \mathrm{~cm} / \mathrm{s}$, while the eastern side of Java Island has relatively low speeds with a range of 0-20 $\mathrm{cm} / \mathrm{s}$. During this season, the SOC speed at Gilimanuk and Ketapang Ports was 80 and $6 \mathrm{~cm} / \mathrm{s}$ (Figure 5d).

Figure 5 also shows the SOC direction in the Bali Strait, which generally points to the South. This is due to the influence of the bathymetry of the Bali Strait, which leads to the Indian Ocean. Hanifa et al. [45] explained that the bathymetry of the north side of the Bali Strait is relatively shallow about $50 \mathrm{~m}$ and extends to $360 \mathrm{~m}$ on the south side of the water. Some of the eddies formed during the DJF season can also be influenced by various things such as the wind [46], imbalance of the baroclinic layer [47], and differences in salinity [48]. The influence of the season on SOC seems to be more pronounced in the Bali Strait, wherein the DJF season the SOC is lower than the JJA season. Furthermore, the SOC pattern in the four seasons can be simplified into two patterns period, the relaxation and agitation periods. The relaxation period includes the DJF and MAM season, while the agitation period includes the JJA and SON seasons. Largier [49] explained that the relaxation period of SOC occurs when a barotropic pressure difference appears that allows an upwelling event to occur. Meanwhile, the SOC agitation period occurs when a storm occurs in the ocean. Furthermore, the periods of relaxation and agitation are characterized by varying low and high wind speeds, respectively [50]. Observation made by Pranowo [51] also found that the SOC in the Bali Strait is related to the DJF season with ranges 2-6 $\mathrm{m} / \mathrm{s}$ and dominant direction from the southeast.
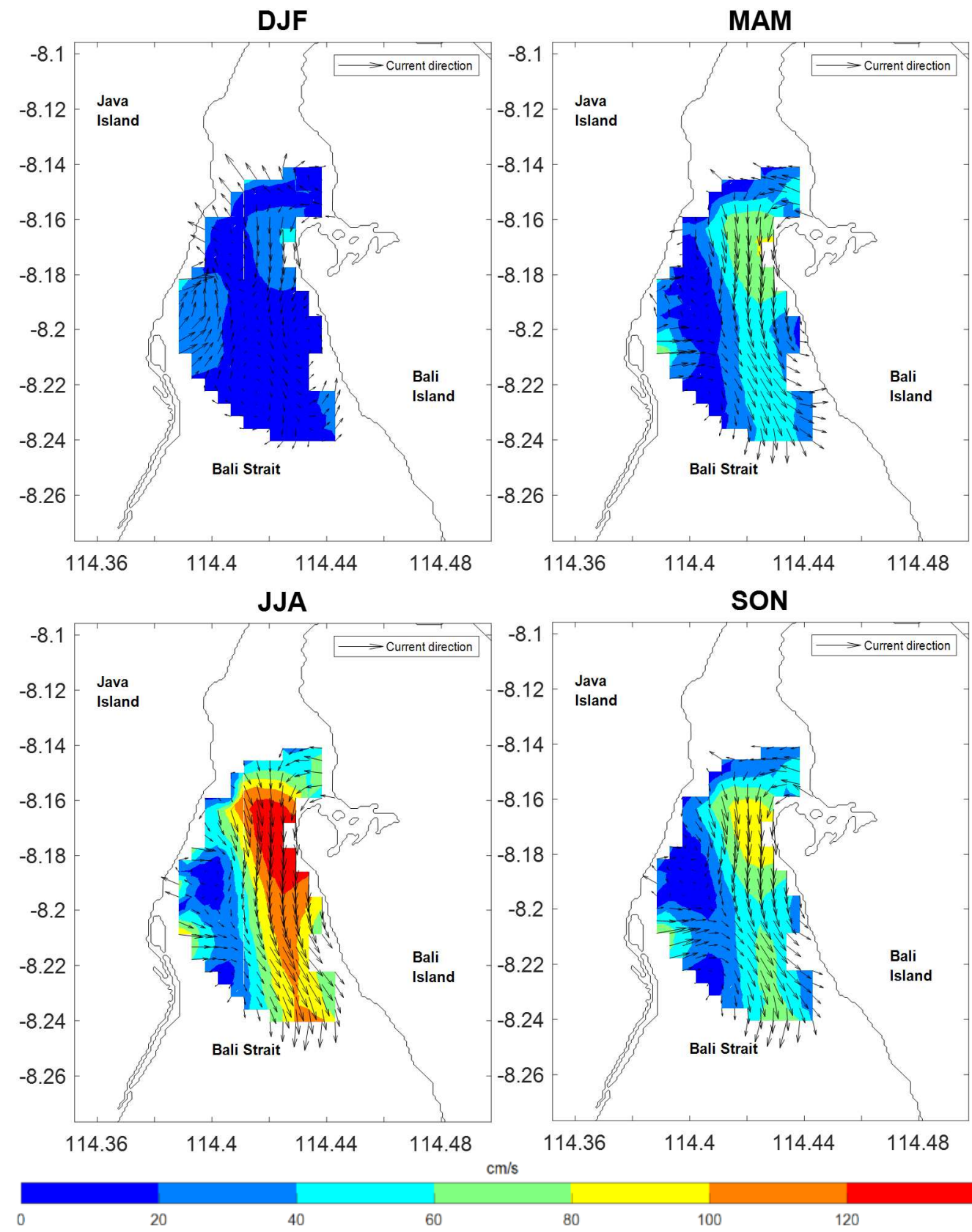

(a)

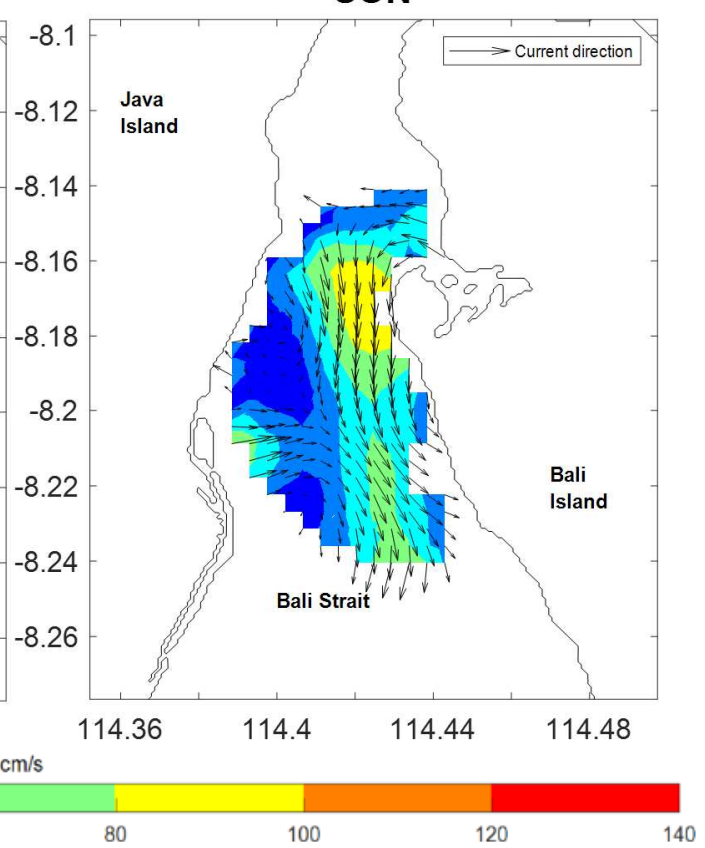

(b)

Fig. 5 The SOC vector in the Bali Strait for each season. The contours indicate the current speed $(\mathrm{cm} / \mathrm{s})$, while the black arrows specify the direction of the current. 


\section{Characteristics of SOC in the Flores Sea}

During the DJF season, the Flores Sea had three different SOC speed patterns. The northern part was high-speed with a predominantly eastward direction, the center was relatively calm, and the southern part tended to be irregular due to the clustering of small islands around it (Figure 6a). High-speed currents were detected on the north side of Rinca Island $\left(8.5^{0}\right.$ south longitude), reaching $35 \mathrm{~cm} / \mathrm{s}$. The SOC speed created at Labuhan Bajo Port tended to be low, with $5 \mathrm{~cm} / \mathrm{s}$ dominating the current direction to the north. Furthermore, during the MAM season, SOC conditions in the Flores Sea tended to be calm on the west side of the East Nusa Tenggara Island, while high currents were detected close to the east side of Komodo Island, which might reach $31 \mathrm{~cm} / \mathrm{s}$ with the dominant current direction towards the southwest (Figure 6b). It can also be seen that on the north side of the Flores Sea, the direction of the current moving to the east began to turn west in the middle waters of the Flores Sea. The same thing happened on the south side of the Flores Sea, which was initially the current direction that went north turned east.

In the JJA season, a maximum SOC speed of $30 \mathrm{~cm} / \mathrm{s}$ was formed near Komodo Island in the northwest direction (Figure 6c). Generally, low SOC velocities occurred on the northern side of the Flores Sea, ranging from $0-15 \mathrm{~cm} / \mathrm{s}$. Considering the western side of the Flores Sea pointed to the southeast and the eastern side of the Flores Sea pointed to the northwest, resulting in the low SOC speeds in the middle of the Flores Sea ( $119.70^{\circ}$ east longitude). The SOC speed at Labuhan Bajo Port was obtained as much as $5 \mathrm{~cm} / \mathrm{s}$.
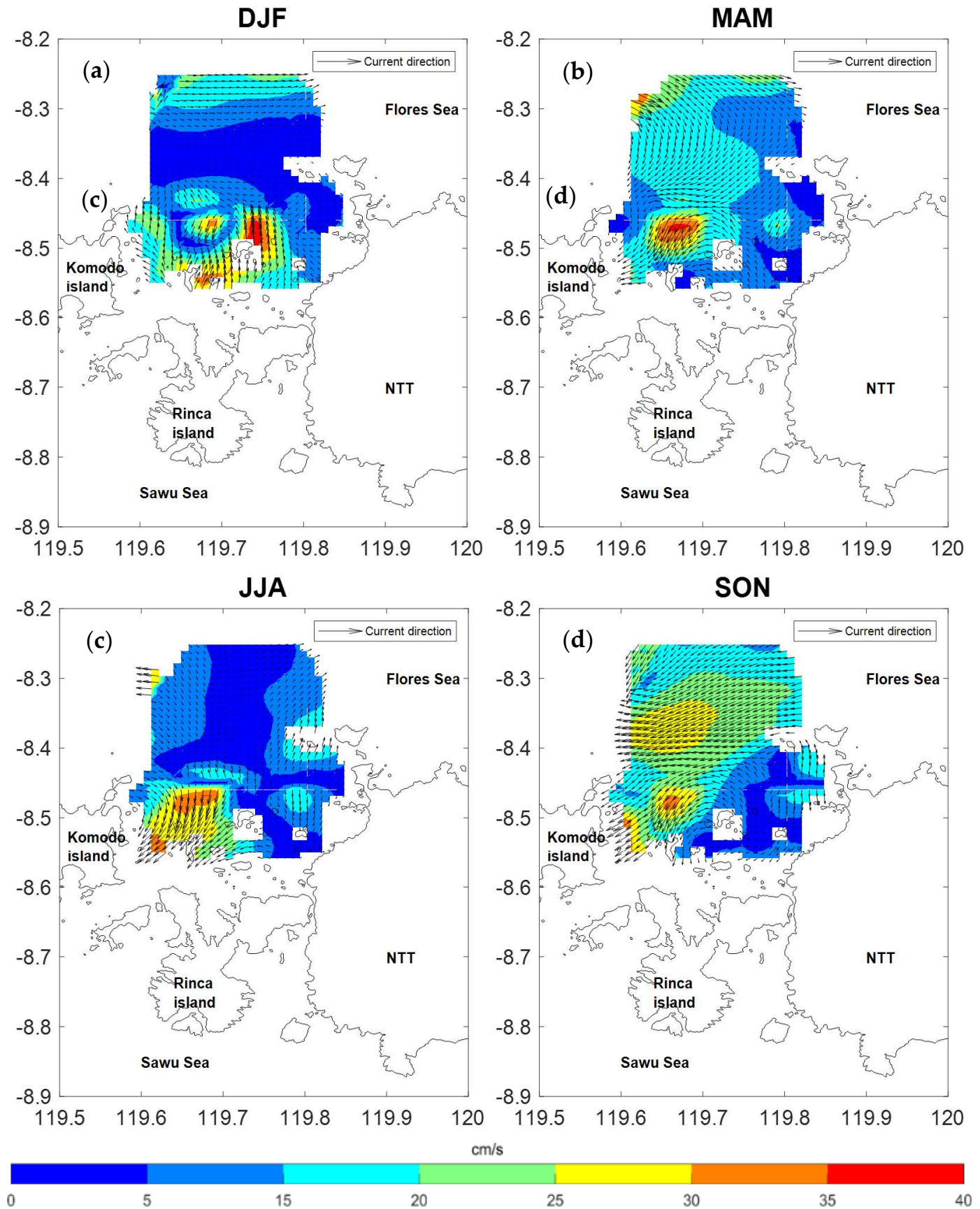

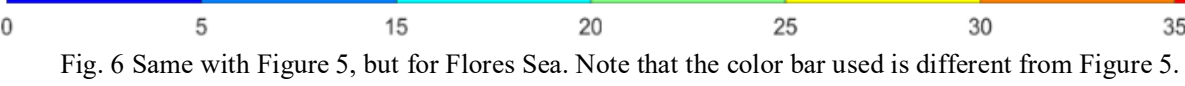


After that, during the SON season, the dominance of high SOC speeds almost covered the study area, in the range of 15$30 \mathrm{~cm} / \mathrm{s}$ while the lower SOC speeds occurred on the west side of East Nusa Tenggara Island with a range of $0-15 \mathrm{~cm} / \mathrm{s}$. The current direction in this season was dominated towards the southwest, except for the west side of East Nusa Tenggara Island that headed north and then turned to the southwest in the middle of the water. Meanwhile, the SOC speed in the Labuhan Bajo Port was measured and the result was $5 \mathrm{~cm} / \mathrm{s}$ (Figure 6d).

In general, the SOC speed in the Flores Sea is lower when compared to the Bali Strait, which only ranges from 0-40 $\mathrm{cm} / \mathrm{s}$. Some of the Bali Strait topographical differences are that the Flores Sea has many small islands, especially between Komodo and NTT islands, causing the currents to move faster in the region (Figures 5 and 6). The SOC in the Flores Sea has a distinctive pattern in diurnal variations, especially in small island clusters. Furthermore, it is important to note that the SOC speed of the eastern side of Komodo Island was erratic throughout the season due to the influence of topography (such as the existence of small islands) that changes the dominant pattern of the Flores Sea SOC. When considering the bathymetric profile, the north side of the Flores Sea has a bathymetry compared to the south side. This causes the current to move calmer on the north side compared to the south side, which tends to be higher due to the presence of small islands in these waters. At either the maximum or minimum SOC speed in the Flores Sea, the current direction is dominated to the southwest. A study conducted by Webb [52] explains that small islands act as a barrier and can disrupt the dominant current pattern.

Moreover, what needs to be paid attention is that most of the year, the SOC direction is dominant towards the east side of Komodo Island (Figures 6b, c, and d). Thus, it is indicated that a lot of deposits might accumulate there, which in turn can change the morphology of the coastal zone. Sea currents and waves leading to the coast can contribute to the morphological changes in the coastal zone as in the form of sediments [53]. Specifically, Taniguchi et al. [54] explain that residual currents affect sediment deposition on the coast.

Besides, SOC in the Flores Sea in this study tends not to be influenced by seasons. A numerical study conducted by Rizki [55] found that SOC velocity in the Flores Sea in the DJF season was higher but not too significant compared to the JJA season, at 3.7 and $3.5 \mathrm{~m} / \mathrm{s}$. During the DJF season, SOC flows strongly to the east, especially along the coast of the Nusa Tenggara archipelago. Meanwhile, during the JJA season, SOC still flows strongly to the east, although not as strong as during the DJF season. During this season, the SOC moving westward widens in the northern part of the Flores Sea [27]. This is different from the Java Sea, which is geographically directly connected to the Flores Sea but is influenced by the DJF and JJA seasons [56]. However, the maximum SOC speed in the Flores Sea is still low compared to the maximum SOC speed of the Bali Strait, at 40 and $140 \mathrm{~cm} / \mathrm{s}$, respectively.

\section{SOC Characteristics on the Crossing}

The direction and speed of the SOC for the crossing route in Bali Strait and Flores Sea are presented in Figures $7 \mathrm{a}$ and $\mathrm{b}$ with quiver analysis. It is a simple illustration to see the change speed and direction of the SOC with time. The distance Ketapang to Gilimanuk and Labuhan Bajo Ports to point $\mathrm{X}$ was 4.33 and $12 \mathrm{~km}$, respectively. The HF Radar spatial resolution range was $0.0045^{0}(\sim 500 \mathrm{~m})$. Referring to every $1^{0}$ in the equator, the value was $\sim 111 \mathrm{~km}$, meaning that there might be 8 grids in the Bali Strait and 24 grids in the Flores Sea. It can be seen in the Bali Strait (Figure 7a), points 3 and 4 became points of change in the current direction due to the eddy effect mentioned in the previous explanation. It is noteworthy that the influence of ocean waves was not considered in this study.

Figure 7a visualizes that the SOC speed in the Bali Strait generally fluctuated throughout the month. On the eastern side of Java Island, the SOC speed was high in JanuaryFebruary with a range of $30-45 \mathrm{~cm} / \mathrm{s}$, while on the west side of Bali Island, it was high in October and February-May with a range of $24-83 \mathrm{~cm} / \mathrm{s}$. The Low SOC speed on the Java side occurred in November-December with a span of 2-4 cm/s. Meanwhile, on the west side of Bali Island occurred in January with a range of $3-23 \mathrm{~cm} / \mathrm{s}$. It is noted that from June to September, the direction of the Bali Strait currents was dominant towards the northeast.

The SOC throughout the month tended to be consistent at several points for shipping crossings (Figure $7 \mathrm{~b}$ ). Points 1-15 show that SOC tended to consistently point west in October, November, February, March, and May. Besides, the current was directed northeast in July, southeast in April, southwest in June, August, and September. Mostly, in December and January, the direction of the flow was not obvious. At points 16-24 in the Flores Sea, the direction of the SOC that occurred tended to fluctuate, especially in OctoberNovember. The current direction was detected to the north and South in the same month. Other months tended to have the same current direction with a small difference in direction. High current speeds on the Flores Sea crossing route should be watched out for in October, November, February, and May. The current speed for the four months ranged from 20 $32 \mathrm{~cm} / \mathrm{s}$ and low current speed with a range of $1-7 \mathrm{~cm} / \mathrm{s}$.

The SOC is closely related to shipping aspects, especially in Indonesian waters. However, there has not been a study on shipping safety yet. In general, the SOC direction on the ship crossing route in the Bali Strait is generally dominated towards the South around the Bali side (red box, Figure 7a). Another case around the Java side (blue box, Figure 7a), is that the formed SOC tends to be irregular throughout the month. Thus, this area needs special attention to support shipping safety in the Bali Strait. Apart from supporting the safety of shipping crossings, the results of the SOC direction mapping (Figure 7) can be used as a benchmark for the efficient consumption of ship fuels. Moving a ship in the direction of the current requires much less fuel than the direction of the current opposite [57], [58].

However, this can be maximized if the surface wind direction is also in the same direction as the ship's motion. Further study is required to determine the best shipping time by combining the effects of wind speed and direction with the surface ocean currents. A study on SOC in the Bali Strait was conducted by Bayhaqi [59], which found that the direction of currents in the Bali Strait for the period of 2006-2012 was dominant from the southeast. The direction of currents in the Flores Sea was predominantly influenced by the west monsoon [27]. 

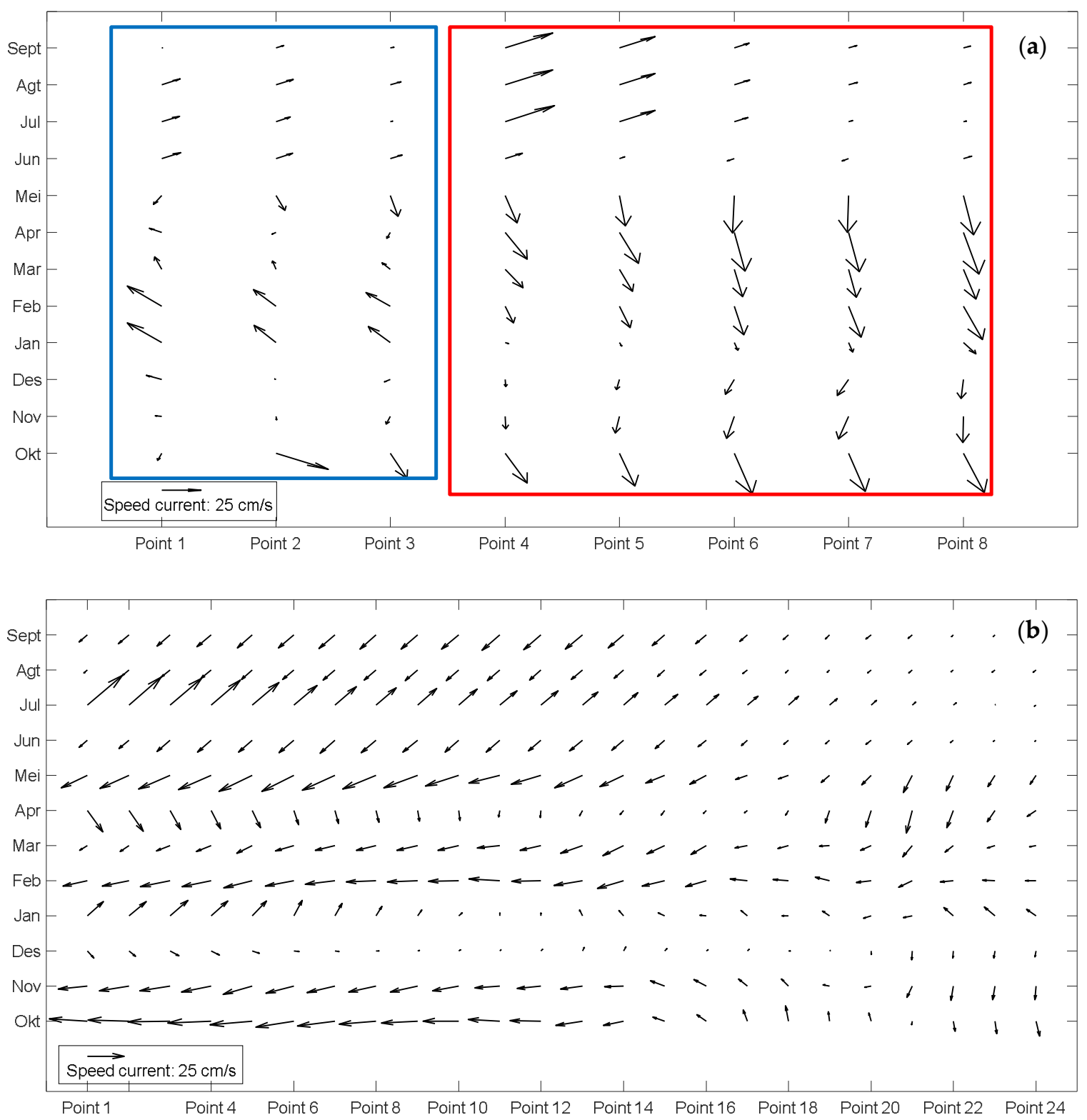

Fig. 7 (a) The general pattern of the SOC ship crossings in the Bali Strait throughout the month. Point 1 and 8 is associated with Ketapang and Gilimanuk Port, respectively. The blue and red boxes represent the different SOC contrasts that occur in the Bali Strait; (b) Same with (a) but for Labuhan Bajo Port. Point 1 and 24 is associated with Point X and Labuhan Bajo Port, respectively.

\section{E. SOC Controlling Factor}

Figure 8a shows that Ketapang Port has a tidal pattern of a semi-diurnal type wherein a day there are a maximum of two high tides and a minimum of low tides. This is evidenced by two maximum values and two minimum values. This is also related to the diurnal pattern of surface current velocity where two waves are formed. This semi-diurnal tidal pattern occurred due to the semi-diurnal tide components of M2 and S2, which were greater than the diurnal tide components of $\mathrm{K} 1$ and $\mathrm{O} 1$. Furthermore, there was no significant effect when the current speed was compared to the wind speed. Wind speeds tended to be high at 00-06 UTC (08.00-14.00 local time). It was seen that the wind speed dropped drastically after 5 UTC until the next day, 21 UTC. This occurs due to the warming of the air by the sun. Coastal areas tend to experience high wind speed from morning to daytime due to the displacement of air masses from the oceans that have cooled at night. In addition, wind speed patterns increase with increased solar radiation energy (dotted line).

The relationship between SOC and tides-wind speed in the Bali Strait in Figure 8a was then analyzed using NCC analysis (Equation 13-14). This was to avoid analysis errors and lead to a more objective and exact interpretation. It might be seen that the NCC value for water level was higher than the wind. This means that tides significantly influenced the dominant SOC pattern in the Bali Strait. Besides, the influence of wind and tides on SOC had a direct effect (immediately), as evidenced by the NCC peak of both relations at lag 0 . If the results of Figure 8a are compared to Figure 8b, it turns out that the SOC speed pattern is almost identical to the water level pattern to that of Figure 8a. 

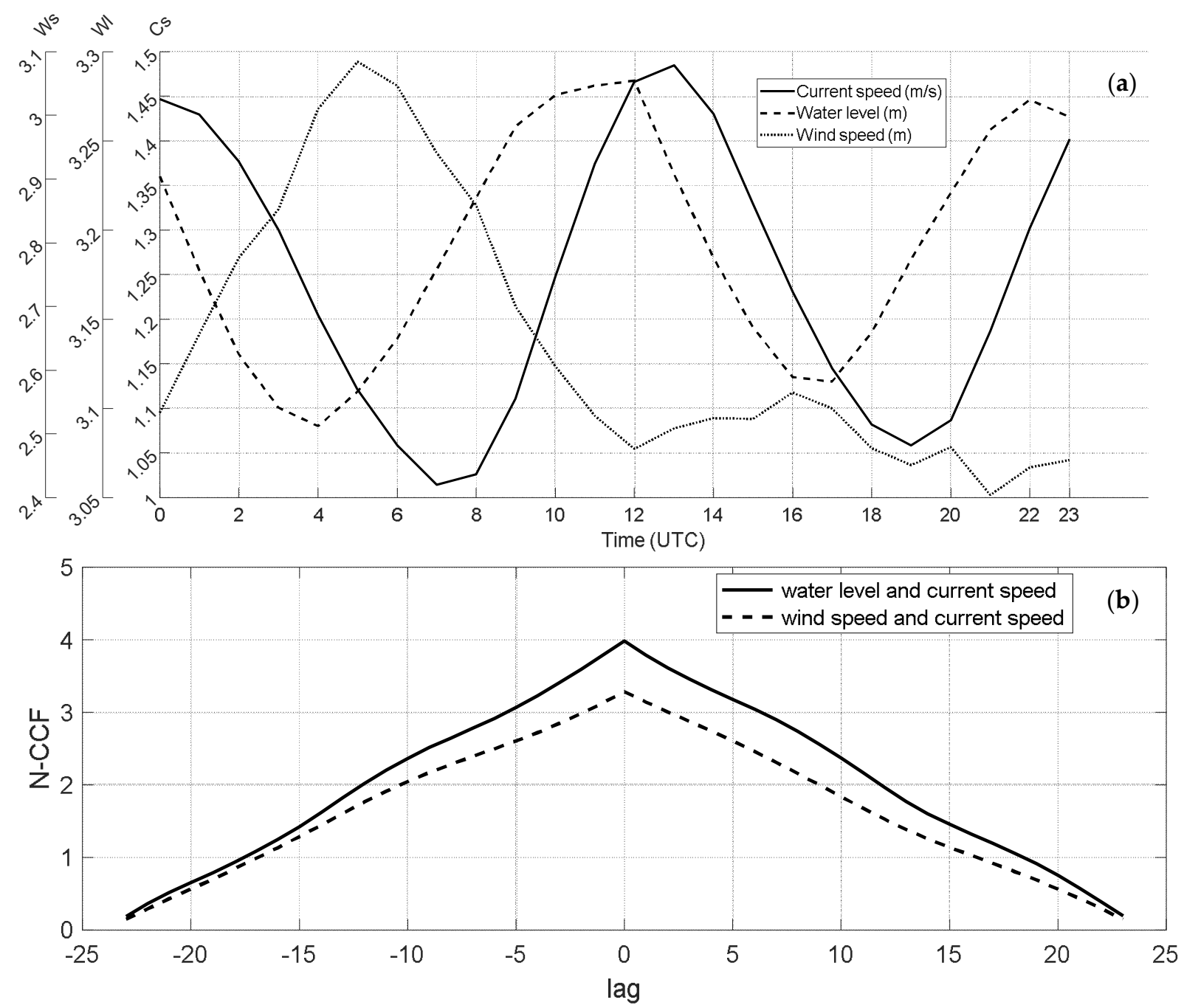

Fig. 8 (a) Comparison of water level (dashed line) and wind speed (dotted line) to SOC speed (the solid line) at Ketapang Port; (b) The interpretation of part (a) is carried out using the NCC to see the most dominant controlling on the SOC.

Figure 8 and the analysis above explain that tides have more influence on surface currents than wind speeds in the Bali Strait. As for the Flores Sea, the relationship pattern of wind speed, water level, and surface currents cannot be determined for the absence of an AWS as a water level data supplier. However, this can be anticipated by looking at the distribution (scatter) of the relationship between $u$ and $v$ SOC components. If the distribution is in an ellipse form, the SOC predominantly influences tides [33], [60]. This is because the SOC component is the resultant movement of the major and minor axes. These results are presented in Figure $9 a-d$ for plotting each season in the Flores Sea. It can be shown that the (zonal-meridional) $(u-v)$ pattern produced every season did not form an ellipse pattern like the $u-v$ pattern in the Bali Strait (not shown here). Thus, it can be said that tides do not influence SOC in the Flores Sea. Besides, there is no water level observation device such as AWS from the Flores Sea search results, especially those close to the HF Radar installation. Whereas the AWS is a device in providing sealevel information in tourists area, especially on Komodo Island, it is predominantly used in Indonesian waters.

Furthermore, Figure 8a again visualizes the high wind speed in the Bali Strait at 00-06 UTC is due to the balance of the radiation flux received or released from the land.
Radiation flux values are generally negative and constant at night and positive along with the sun's peak during the day. The radiation flux includes flux sensible heat, latent flux heat, and flux storage heat. The location of the observation is the boundary between land and sea. Accordingly, there may be differences in the radiation flux received. According to Roland [61], two things affect the balance of radiation flux on the coast. First, the flux storage heat conditions in the oceans can reach hundreds of meters due to the influence of currents and waves. Second, the specific heat of water greater than land causes the oceans to absorb and store solar radiation during the day and release it at night. High specific heat requires a longer time for both absorption, storage, and release. As a result, there might be a time lag for transferring radiation flux between the oceans and the land. In normal and mainland, the radiation flux on land occurs simultaneously near the peak of the sun. However, due to the location of the study is close to the sea, it causes a higher flux storage heat absorbed compared to land. Thus, it disrupts the balance of radiation flux on the mainland resulting in high wind speeds before noon. The wind speed pattern is presented in Figure 8a, similar to the result that the heat flux is felt diurnal where it is high during the day and constant at night [62]. 

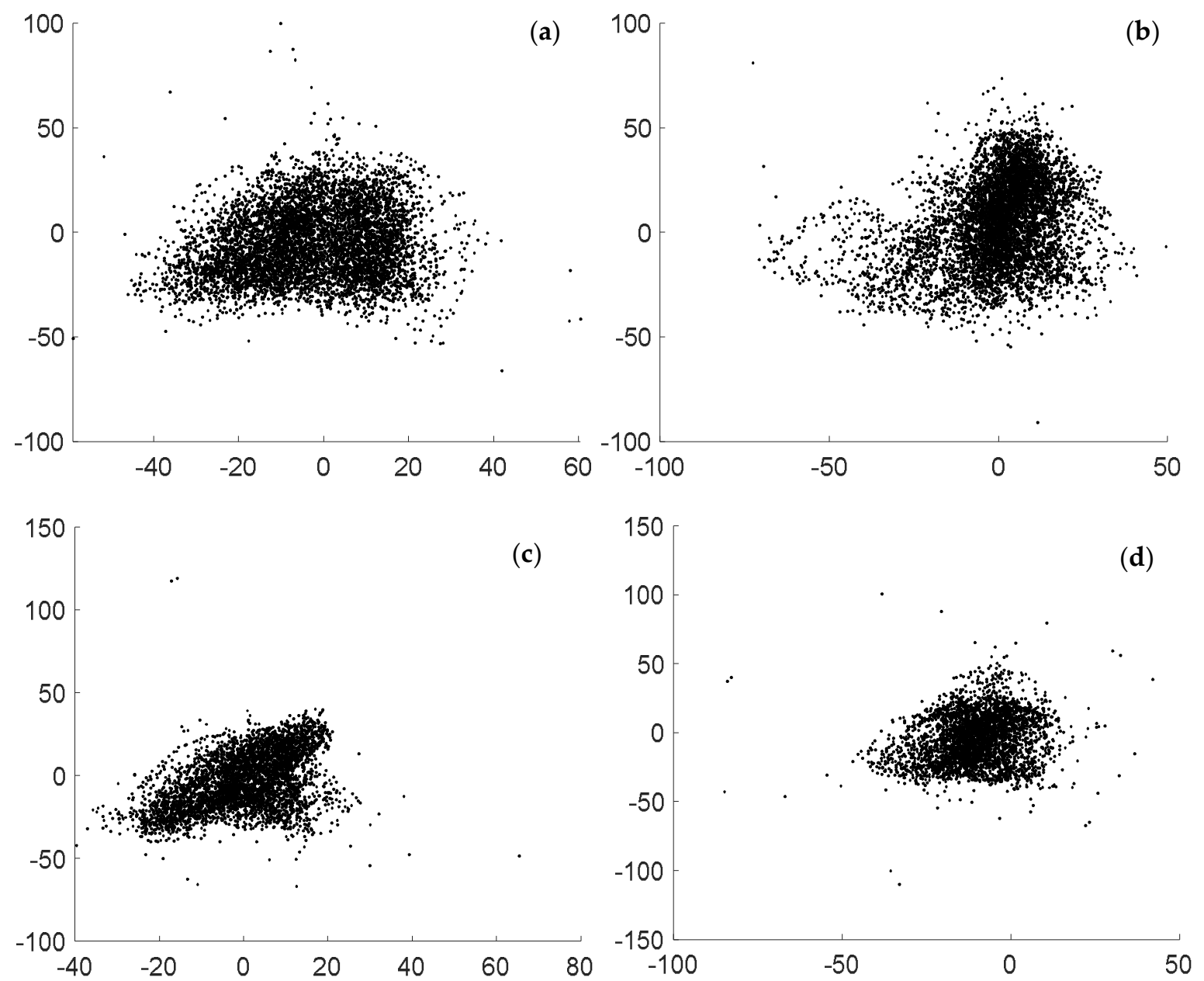

Fig. 9 Scattering of $u-v(\mathrm{~m} / \mathrm{s})$ SOC components from HF Radar for DJF (a), MAM (b), JJA (c), SON (d) season in the Flores Sea. The $u$ and $v$ components are represented by the $\mathrm{x}$ and $\mathrm{y}$ axes, respectively.

Referring to Figures 5 and 6, even though they are in the same archipelago, the Bali Strait and the Flores Sea make different contributions regarding SOC generation. The Bali Strait has a bathymetric slope that tends to have its currents influenced by tides. Meanwhile, the Flores Sea, which has relatively flat bathymetry not influenced by tides. More detail in Figure $8 \mathrm{~b}$ also show the NCC water level is higher than the wind. The influence of wind and tides on the SOC has a direct effect (immediately), as evidenced by the peak of the NCC of the two relations at lag 0 . The study conducted by Cutroneo et al. [36] in the Tyrrhenian Sea, Italy, indicates similar results where the average bathymetry is $50 \mathrm{~m}$, not much different from the center of the Bali Strait by about 50-360 m [45]. However, further research is still needed to determine the correlation between SOC and tides to sea depth. Furthermore, the obstruction in the form of small islands in the Flores Sea also disturbs the dominant SOC pattern, comparing this pattern with currents far from the island; the values tend to be homogeneous (Figure 6).

Studies on seasonal SOC in the Bali Strait and the Flores Sea are rarely done, even in Indonesia. Some research done by Syamsudin et al. [63] and Hanifa et al. [45] tends to be done in the short term and based on the model by Berlianty and Yanagi [64] and Hasanah [65], as a result of which it is challenging to capture seasonal patterns. This paper offers novelty in the form of utilization of HF Radar to get seasonal
SOC pattern. The next research can be developed for other applications.

\section{CONCLUSION}

The first measurement, utilization, and analysis of HF Radar in Indonesia have been carried out in the Bali Strait and the Flores Sea. The low-pass filtering was used in this paper to validation. The seasonal effect influences the Bali Strait of the SOC pattern, where the SOC speed in the DJF season is lower than the JJA season. Meanwhile, the SOC direction in the Bali Strait is predominantly southward due to the influence of the bathymetry. On the other hand, this study also obtained that the SOC speed on the north side of the Flores Sea generally has a uniform speed, but the SOC speed becomes erratic on the south side of the Flores Sea. This is due to the influence of topography that changes the dominant SOC pattern. Then, the SOC pattern of crossing routes in the Bali Strait is conducted in this paper. Finally, the SOC in the Bali Strait is influenced by tides, while in the Flores Sea is not. It is based on the comparison SOC, water level, and wind of the NCC methods.

\section{ACKNOWLEDGMENT}

The authors are grateful to the Marine Meteorology Center of BMKG for HF Radar and ADCP data availability. Also, the authors are obliged to anonymous reviewers for their 
comments. This research was funded by the Training and Education Center (Pusdiklat) of BMKG No. HK.08.00/029/KDL/IX/2020.

\section{REFERENCES}

[1] L. R. Wyatt, "Measuring the ocean wave directional spectrum 'First Five' with HF radar," Ocean Dyn., vol. 69, no. 1, pp. 123-144, 2019, doi: $10.1007 / \mathrm{s} 10236-018-1235-8$.

[2] ITU, "Nomenclature of the frequency and wavelength bands used in telecommunications," 2019.

[3] B. Lipa, D. Barrick, and C. Whelan, "A Quality Control Method for Broad-Beam HF Radar Current Velocity Measurements," Journal of Marine Science and Engineering, vol. 7, no. 4. 2019, doi: $10.3390 /$ jmse 7040112 .

[4] Z. Tian et al., "Wave-Height Mapping From Second-Order Harmonic Peaks of Wide-Beam HF Radar Backscatter Spectra," IEEE Trans. Geosci. Remote Sens., vol. 58, no. 2, pp. 925-937, 2020, doi: 10.1109/TGRS.2019.2941823

[5] Y. Tian, B. Wen, Z. Li, Y. Yin, and W. Huang, "Analysis and Validation of an Improved Method for Measuring HF Surface Wave Radar Antenna Pattern," IEEE Antennas Wirel. Propag. Lett., vol. 18, no. 4, pp. 659-663, 2019, doi: 10.1109/LAWP.2019.2900562.

[6] C.-A. Guérin and S. T. Grilli, "A probabilistic method for the estimation of ocean surface currents from short time series of HF radar data," Ocean Model., vol. 121, pp. 105-116, 2018, doi: https://doi.org/10.1016/j.ocemod.2017.11.010.

[7] D. Crombie, "Doppler spectrum of sea echo at $13.56 \mathrm{Mc} . / \mathrm{s.}$," Nature, vol. 175 , no. 4459 , pp. 681-682, 1955, doi: 10.1038/175681a0.

[8] A. Rubio et al., "HF Radar Activity in European Coastal Seas: Next Steps toward a Pan-European HF Radar Network," Front. Mar. Sci., vol. 4, p. 8, 2017, doi: 10.3389/fmars.2017.00008

[9] H. Roarty et al., "The global high frequency radar network," Frontiers in Marine Science, vol. 6. p. 164, 2019.

[10] A. Caballero et al., "Integration of HF Radar Observations for an Enhanced Coastal Mean Dynamic Topography," Front. Mar. Sci., vol. 7, p. 1005, 2020, doi: 10.3389/fmars.2020.588713

[11] Y. Liu, C. R. Merz, R. H. Weisberg, B. K. O'Loughlin, and V. Subramanian, "Data Return Aspects of CODAR and WERA HighFrequency Radars in Mapping Currents BT - Observing the Oceans in Real Time," R. Venkatesan, A. Tandon, E. D'Asaro, and M. A. Atmanand, Eds. Cham: Springer International Publishing, 2018, pp. 227-240.

[12] S. Cosoli and S. de Vos, "Interoperability of Direction-Finding and Beam-Forming High-Frequency Radar Systems: An Example from the Australian High-Frequency Ocean Radar Network," Remote Sensing , vol. 11, no. 3. 2019, doi: 10.3390/rs11030291.

[13] JCOMM, "High Frequency Radar Network, 10th Session of the JCOMM Observation Coordination Group," Jakarta, 2019.

[14] K. Aoki and T. Kataoka, "High-frequency ocean radar derived characteristics of sea surface currents in the Ariake Sea, Japan," $J$. Oceanogr., vol. 74, no. 4, pp. 431-437, 2018, doi: 10.1007/s10872018-0464-2.

[15] L. Ren, Z. Hu, and M. Hartnett, "Short-Term Forecasting of Coastal Surface Currents Using High Frequency Radar Data and Artificial Neural Networks," Remote Sensing, vol. 10, no. 6. 2018, doi: 10.3390/rs10060850.

[16] A. Orasi et al., "HF radar for wind waves measurements in the MaltaSicily Channel," Measurement, vol. 128, pp. 446-454, 2018, doi https://doi.org/10.1016/j.measurement.2018.06.060.

[17] Y. Li and R. Toumi, "Improved Tropical Cyclone Intensity Forecasts by Assimilating Coastal Surface Currents in an Idealized Study," Geophys. Res. Lett., vol. 45, no. 18, pp. 10,10-19,26, Sep. 2018, doi: https://doi.org/10.1029/2018GL079677.

[18] L. Lukijanto, N. Hashimoto, and M. Yamashiro, "A Comparison of analysis methods for estimating directional wave spectrum from $\mathrm{HF}$ Ocean Radar," Mem. Fac. Eng. Kyushu Univ., vol. 69, pp. 163-185, Dec. 2009.

[19] Iswandi, R. Hidayat, B. Setiyanto, and S. B. Wibowo, "Study on Detection Mechanism of HF Radar for Early Tsunami Detection and Comparison to Other Tsunami Sensors," in 2019 11th International Conference on Information Technology and Electrical Engineering (ICITEE), 2019, pp. 1-6, doi: 10.1109/ICITEED.2019.8929984.

[20] D. Barrick, M. Evans, and B. Weber, "Ocean surface currents mapped by radar," in Proceedings of the 1978 IEEE First Working Conference on Current Measurement, 1978, vol. 1, pp. 59-65, doi:
10.1109/CCM.1978.1158377.

21] L. Renault, J. C. McWilliams, and S. Masson, "Satellite Observation of Imprint of Oceanic Current on Wind Stress by Air-Sea Coupling," Sci. Rep., vol. 7, no. 1, p. 17747, 2017, doi: 10.1038/s41598-01717939-1.

[22] E. Armenio, F. De Serio, and M. Mossa, "Analysis of data characterizing tide and current fluxes in coastal basins," Hydrol. Earth Syst. Sci., vol. 21, no. 7, pp. 3441-3454, 2017, doi: 10.5194/hess-213441-2017.

[23] K. Wyrtki, "An equatorial jet in the Indian Ocean," Science (80-. )., vol. 181, no. 4096, pp. 262-264, Jul. 1973, doi 10.1126/science. 181.4096 .262 .

[24] S. Pond and G. L. Pickard, "12 - Waves," S. POND and G. L. B. T.-I D. O. (Second E. PICKARD, Eds. Oxford: Butterworth-Heinemann, 1983, pp. 207-252.

[25] R. Stewart, Introduction to Physical Oceanography. 2008.

[26] K. Ogata, S. Seto, R. Fuji, T. Takahashi, and H. Hinata, "Real-Time Tsunami Detection with Oceanographic Radar Based on Virtual Tsunami Observation Experiments," Remote Sensing , vol. 10, no. 7. 2018, doi: 10.3390/rs10071126.

[27] Bakosurtanal, Atlas Nasional Indonesia Vol. 1, 1st ed. Bogor: Bakosurtanal, 2008.

[28] J. D. Paduan, M. S. Cook, and V. M. Tapia, "Patterns of upwelling and relaxation around Monterey Bay based on long-term observations of surface currents from high frequency radar," Deep Sea Res. Part II Top. Stud. Oceanogr., vol. 151, pp. 129-136, 2018, doi: https://doi.org/10.1016/j.dsr2.2016.10.007.

[29] R. E. Thomson and W. J. Emery, "Chapter 5 - Time Series Analysis Methods," R. E. Thomson and W. J. B. T.-D. A. M. in P. O. (Third E Emery, Eds. Boston: Elsevier, 2014, pp. 425-591.

[30] U. Mackenroth, Rational Transfer Functions. In: Robust Control Systems. Berlin, Heidelberg: Springer, 2004.

[31] R. Valbuena et al., "Evaluating observed versus predicted forest biomass: R-squared, index of agreement or maximal information coefficient?," Eur. J. Remote Sens., vol. 52, no. 1, pp. 345-358, Jan. 2019, doi: 10.1080/22797254.2019.1605624.

[32] T. Lee, S. Fournier, A. L. Gordon, and J. Sprintall, "Maritime Continent water cycle regulates low-latitude chokepoint of global ocean circulation," Nat. Commun., vol. 10, no. 1, p. 2103, 2019, doi: 10.1038/s41467-019-10109-z.

[33] M. Foreman, "Manual for Tidal Currents Analysis and Prediction," vol. 78 , Oct. 2004

[34] E. León-Castro, E. Avilés-Ochoa, and J. M. Merigó, "Induced Heavy Moving Averages,” Int. J. Intell. Syst., vol. 33, no. 9, pp. 1823-1839, Sep. 2018, doi: https://doi.org/10.1002/int.21916.

[35] A. Gogolou, T. Tsandilas, T. Palpanas, and A. Bezerianos, "Comparing Similarity Perception in Time Series Visualizations," IEEE Trans. Vis. Comput. Graph., vol. 25, no. 1, pp. 523-533, 2019, doi: 10.1109/TVCG.2018.2865077.

[36] L. Cutroneo, G. Ferretti, D. Scafidi, G. D. Ardizzone, G. Vagge, and M. Capello, "Current observations from a looking down vertical V ADCP: interaction with winds and tide? The case of Giglio Island (Tyrrhenian Sea, Italy)," Oceanologia, vol. 59, no. 2, pp. 139-152, 2017, doi: https://doi.org/10.1016/j.oceano.2016.11.001.

[37] G. Wei et al., "Assessment of HF Radar in Mapping Surface Currents under Different Sea States," J. Atmos. Ocean. Technol., vol. 37, no. 8, pp. 1403-1422, doi: 10.1175/JTECH-D-19-0130.1.

[38] Y. Tian, B. Wen, Z. Li, Y. Hou, Z. Tian, and W. Huang, "Fully digital multi-frequency compact high-frequency radar system for sea surface remote sensing," IET Radar, Sonar Navig., vol. 13, no. 8, pp. 1359_ 1365, Aug. 2019, doi: https://doi.org/10.1049/iet-rsn.2018.5655.

[39] L. P. Corgnati et al., "Implementation and Validation of the ISMAR High-Frequency Coastal Radar Network in the Gulf of Manfredonia (Mediterranean Sea)," IEEE J. Ocean. Eng., vol. 44, no. 2, pp. 424445, 2019, doi: 10.1109/JOE.2018.2822518.

[40] Y. Liu and R. H. Weisberg, "Ocean Currents and Sea Surface Heights Estimated across the West Florida Shelf," J. Phys. Oceanogr., vol. 37 no. 6, pp. 1697-1713, Jun. 2007, doi: 10.1175/JPO3083.1.

[41] Y. Liu, R. H. Weisberg, C. R. Merz, S. Lichtenwalner, and G. J. Kirkpatrick, "HF Radar performance in a low-energy environment: CODAR SeaSonde experience on the West Florida Shelf*," J. Atmos Ocean. Technol., vol. 27, no. 10, pp. 1689-1710, Oct. 2010, doi: 10.1175/2010JTECHO720.1.

[42] S. Saviano, D. Cianelli, E. Zambianchi, F. Conversano, and M. Uttieri, "An Integrated Reconstruction of the Multiannual Wave Pattern in the Gulf of Naples (South-Eastern Tyrrhenian Sea, Western Mediterranean Sea)," Journal of Marine Science and Engineering , 
vol. 8, no. 5. 2020, doi: 10.3390/jmse8050372.

[43] L. Ren, M. Wang, H. Cai, Z. Hu, Q. Yang, and M. Hartnett, "Characteristics of coastal currents based on High Frequency radar and ADCP observations in the Strait of Georgia," IOP Conf. Ser. Earth Environ. Sci., vol. 189, p. 52042, 2018, doi: 10.1088/17551315/189/5/052042.

[44] A. Sentchev, P. Forget, Y. Barbin, and M. Yaremchuk, "Surface circulation in the Iroise Sea (W. Brittany) from high resolution HF Radar mapping,” J. Mar. Syst., vol. 109-110, pp. S153-S168, 2013 doi: https://doi.org/10.1016/j.jmarsys.2011.11.024.

[45] A. D. Hanifa et al., "Tomographic measurement of tidal current and associated 3-h oscillation in Bali Strait," Estuar. Coast. Shelf Sci., vol. 236, p. 106655, 2020, doi: https://doi.org/10.1016/j.ecss.2020.106655.

[46] A. Schaeffer, A. Gramoulle, M. Roughan, and A. Mantovanelli, "Characterizing frontal eddies along the East Australian Current from HF Radar observations," J. Geophys. Res. Ocean., vol. 122, no. 5, pp. 3964-3980, May 2017, doi: 10.1002/2016JC012171.

[47] J. Guo, Z. Zhang, C. Xia, B. Guo, and Y. Yuan, "Topographicbaroclinic instability and formation of Kuroshio current loop," Dyn Atmos. Ocean., vol. 81, pp. 15-29, 2018, doi: https://doi.org/10.1016/j.dynatmoce.2017.11.002.

[48] R. J. Brokaw, B. Subrahmanyam, and S. L. Morey, "Loop current and Eddy-driven salinity variability in the Gulf of Mexico," Geophys. Res. Lett., vol. 46, no. 11, pp. 5978-5986, Jun. 2019, doi: 10.1029/2019GL082931.

[49] J. L. Largier, B. A. Magnell, and C. D. Winant, "Subtidal circulation over the northern California shelf," J. Geophys. Res. Ocean., vol. 98 , no. C10, pp. 18147-18179, Oct. 1993, doi: 10.1029/93JC01074.

[50] M. K. Gough, N. Garfield, and E. McPhee-Shaw, "An analysis of HF radar measured surface currents to determine tidal, wind-forced, and seasonal circulation in the Gulf of the Farallones, California, United States," J. Geophys. Res. Ocean., vol. 115, no. C4, Apr. 2010, doi: 10.1029/2009JC005644.

[51] W. S. Pranowo, "Sirkulasi arus vertikal di Selat Bali pada monsun tenggara 2004," Palembang, 2006.

[52] D. J. Webb, "A simple model of the effect of the Kerguelen Plateau on the strength of the Antarctic Circumpolar Current," Geophys. Astrophys. Fluid Dyn., vol. 70, no. 1-4, pp. 57-84, Jun. 1993, doi: 10.1080/03091929308203587.

[53] G. Franz, M. Delpey, D. Brito, L. Pinto, P. Leitão, and R. Neves, "Modelling of sediment transport and morphological evolution under the combined action of waves and currents," Ocean Sci. Discuss., pp.
1-26, Mar. 2017, doi: 10.5194/os-2017-8.

[54] N. Taniguchi, C.-F. Huang, M. Arai, and B. M. Howe, "Variation of Residual Current in the Seto Inland Sea Driven by Sea Level Difference Between the Bungo and Kii Channels," J. Geophys. Res. Ocean., vol. 123, no. 4, pp. 2921-2933, Apr. 2018, doi: https://doi.org/10.1029/2017JC013618.

[55] T. Rizki, "Studi pemodelan numerik oseanografi untuk mendukung perencanaan manajemen wilayah pesisir terpadu di Taman Nasional Komodo," Appl. Technol. Comput. Sci. J., vol. 1, pp. 114-123, Dec. 2018, doi: 10.33086/atcsj.v1i2.859.

[56] B. Sadhotomo, "Review of environmental features of the Java Sea," Indones. Fish. Res. J., vol. 12, no. 2, pp. 129-157, 2006, doi http://dx.doi.org/10.15578/ifrj.12.2.2006.129-157.

[57] Y.-C. Chang, R.-S. Tseng, G.-Y. Chen, P. C. Chu, and Y.-T. Shen, "Ship routing utilizing strong ocean currents," J. Navig., vol. 66, no. 6, pp. 825-835, 2013, doi: DOI: 10.1017/S0373463313000441.

[58] R. Yan, S. Wang, and Y. Du, "Development of a two-stage ship fuel consumption prediction and reduction model for a dry bulk ship," Transp. Res. Part E Logist. Transp. Rev., vol. 138, p. 101930, 2020, doi: https://doi.org/10.1016/j.tre.2020.101930.

[59] A. Bayhaqi, "Kajian pola pergerakan arus di Perairan Selat Bali," Universitas Brawijaya, 2014.

[60] H. Vindenes, K. A. Orvik, H. Søiland, and H. Wehde, "Analysis of tidal currents in the North Sea from shipboard acoustic Doppler current profiler data," Cont. Shelf Res., vol. 162, pp. 1-12, 2018, doi: https://doi.org/10.1016/j.csr.2018.04.001.

[61] S. Roland, "9 - The Atmospheric Boundary Layer," J. M. Wallace and P. V. B. T.-A. S. (Second E. Hobbs, Eds. San Diego: Academic Press, 2006, pp. 375-417.

[62] I. Hamdani et al., "Seasonal and diurnal evaporation from a deep hypersaline lake: The Dead Sea as a case study," J. Hydrol., vol. 562, pp. 155-167, 2018, doi: https://doi.org/10.1016/j.jhydrol.2018.04.057.

[63] F. Syamsudin et al., "Observing Internal Solitary Waves in the Lombok Strait by Coastal Acoustic Tomography," Geophys. Res. Lett., vol. 46, no. 17-18, pp. 10475-10483, Sep. 2019, doi: https://doi.org/10.1029/2019GL084595.

[64] D. Berlianty and T. Yanagi, "Tide and tidal Current in the Bali Strait, Indonesia," J. Mar. Res., vol. 36, pp. 25-36, Jan. 2011, doi: 10.14203/mri.v36i2.39.

[65] P. Hasanah, "Simulated Circulation and Variability in the Bali seaFlores sea based on models of INDESO 2008-2014," IPB University, 2017. 